\title{
NEIBA
}

\section{As cidades-santuário nos EUA e o contra movimento do Texas: o caso da lei $S B-4$}

\author{
Roberta Maria Botelho Bevilacqua
}

Vínculo Institucional: Mestranda em Relações Internacionais no PPGRIUFU. Bolsista CAPES/Brasil pelo INCT/INEU. E-mail: robevilacqua5@hotmail.com.

\section{Resumo:}

Este trabalho tem o objetivo de analisar o movimento das cidadessantuário nos EUA, durante o período da administração Trump, e contrapor essas atividades com ocaso do Texas, através de um estudo de caso da implementação da lei de imigração SB-4.Considerando o contexto atual da política imigratória (2017-presente), de cunho conservador e xenofóbico, as cidades-santuário ganharam destaque pela forma na qual têm procurado lutar contra essas políticas, propiciando ao imigrante maior segurança e dignidade. No caso do Texas, percebe-se uma aproximação maior com os direcionamentos federais, principalmente através da criação da lei SB-4 em 2017, a qual,dentre outras provisões, obriga as forças policiais locais a questionar o status de imigração de quaisquer indivíduos que julguem necessário.Como conclusão, nota-se que o movimento do Texas é contrário a proposta das cidades-santuário, pois, ao desenvolver a SB-4, coloca-se o imigrante e o estado em risco, gerando possibilidades de perdas econômico-sociais.

Palavras-chaves:

Cidades-santuário; Texas; SB-4

\begin{abstract}
:
This paper aims to analyze the movement of sanctuary jurisdictions in the USA during the Trump administration, and to counteract these activities with the case of Texas through a study of the implementation of the immigration law SB-4. Considering the current context of immigration policy, both conservative and xenophobic, the sanctuary cities have been highlighted by the way in which they have sought to fight against these policies, providing the immigrant with greater security and dignity. In Texas' case, there is a greater approximation to federal directions,
\end{abstract}




\section{NEIBA}

\section{VOLUME V}

Dossiê: SimpoRI 2016

\section{6}

especially through the creation of SB-4 in 2017, which, among other provisions, forces local police to question the immigration status of any individuals. In sum, it is noted that the movement of Texas is contrary to the proposal of the sanctuary jurisdictions, because in developing SB-4, the immigrant and the state are put at risk, creating possibilities of economic and social losses.

\section{Keywords:}

Sanctuary jurisdictions; Immigration; USA; Texas; SB-4 


\section{NEİBA}

\section{Introdução}

Desde 20 de janeiro de 2017, quando Donald Trump assume a presidência dos Estados Unidos da América, percebe-se uma nova era no país tanto na área econômica, quanto política e social. O presidente passou a buscar a concretização de medidas já propostas em sua campanha eleitoral, de cunho conservador, no sentido de exacerbar o nacionalismo estadunidense em todas as esferas da sociedade, seguindo o lema de "Make America great again".

No que tange a situação da migração internacional, logo nos primeiros dias de seu governo, o Presidente assinou uma ordem executiva proibindo temporariamente a entrada de cidadãos de países de maioria muçulmana e suspendendo o programa de recepção de refugiados. Ainda, propôs e iniciou protótipos para a construção de um muro físico separando os Estados Unidos do México, de forma a evitar a imigração ilegal e o tráfico de drogas. Esse tipo de medida já caracterizava que o governo Trump não seria um momento fácil para a população imigrante nos EUA, a qual hoje ultrapassa os 43 milhões de pessoas.

Todavia, nota-se que o sentimento de nacionalismo exacerbado e xenofobia não se perpetua em algumas localidades dos Estados Unidos. Ganhando notoriedade principalmente a partir da década de 1980, período no qual a interdependência visualizada no sistema internacional mostrava que as problemáticas de nível global começaram a adquirir também uma escala local, essas localidades, como os estados da Pensilvânia, Nova Jersey e Nova York, se denominaram naquele período de "sanctuary jurisdictions". Assim, desde então, as cidades-santuário nos EUA visam atuar de forma a proteger a situação do imigrante no país, lutando contra certas medidas do governo federal nessa matéria.

Por mais que atualmente os Estados Unidos tenham um movimento santuário forte, que lidera diversas disputas com a administração federal, ainda existem estados que seguem essa mesma linha política conservadora na área imigratória. Esse é o caso de localidades como o Arizona, Alabama e o Texas, foco do estudo aqui pretendido. Por ser um estado de tradição republicana, historicamente já se espera maior alinhamento com o governo central quando esse partido está no poder, mas, ainda assim, o Texas acabou ganhando destaque dentro do país por desenvolver uma legislação que, na prática, proíbe quaisquer cidades ou condados de suas fronteiras a praticarem atividades típicas das cidades-santuário. Assim, a SB-4 tem sido considerada a legislação mais rígida em relação a imigração, mesmo tendo sido precedida por outras em estados de tradição semelhante, como foi o caso do Arizona em 2010.

Dessa maneira, o estudo de caso pretendido aqui busca realizar um levantamento de como as cidadessantuário tem se posicionado atualmente nos EUA, bem como suas diretrizes e atividades em meio a direcionamentos anti-imigração do governo federal. Em contrapartida, o caso da lei SB-4 no Texas surge como um movimento importante de ser analisado, pois não apenas preocupa a população imigrante, mas também colabora para a abertura de precedente para que outros estados conservadores também criem legislações parecidas. Destarte, cabe ressaltar que o presente trabalho foi realizado com apoio da Coordenação de Aperfeiçoamento de Pessoal de Nível Superior - Brasil (CAPES) - Código de financiamento 001.

Para realizar tal estudo, este artigo está dividido em mais duas seções, somadas a uma conclusão ao final. A primeira seção se destina a fazer uma retomada do histórico de criação do movimento santuário nos EUA, passando pela década de 1980, a qual foi importante para a consolidação do movimento, tendo em vista também o cenário internacional que propiciava o engajamento de atores subnacionais na arena externa. Depois, há uma análise da atuação das cidades-santuário desde o início da Era Trump, mostrando de quais maneiras elas tem tentado combater a atual política imigratória. Na segunda seção, mostra-se o surgimento da 


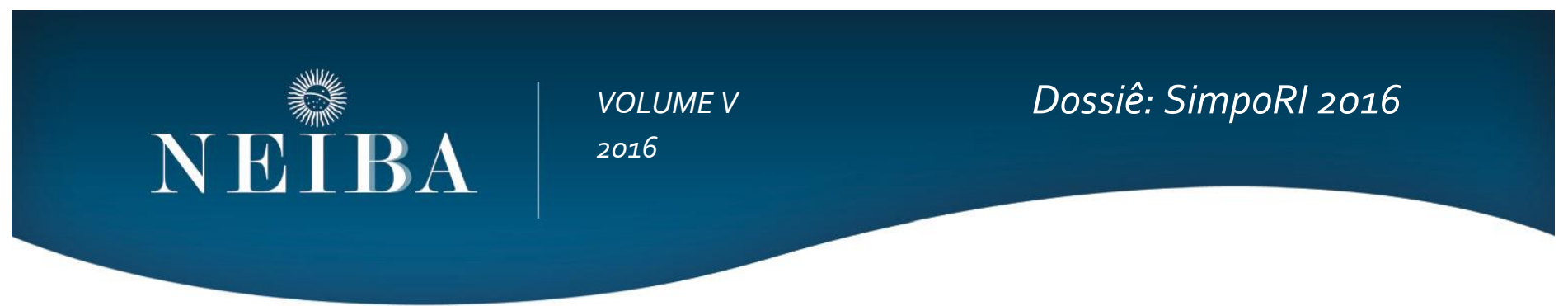

lei SB-4 no Texas, bem como argumentos a favor e contra sua implementação e os desenvolvimentos que se seguiram após a aprovação da lei no legislativo. Como conclusão, é importante ressaltar que esse movimento texano abre um caminho perigoso para a vida da população imigrante, não apenas no estado, mas em todo os EUA, consolidando mais ainda o posicionamento conservador e xenofóbico do governo federal, sem pensar nas perdas econômico-sociais que pode desencadear.

\section{As cidades-santuário nos EUA: passado e presente}

A história das cidades-santuário vem de séculos atrás. Muito antes de ganharem a importância e até mesmo a definição que adquiriram nos dias atuais, essas localidades passaram a representar um abrigo aos primeiros refugiados dos EUA, os escravos fugitivos. Desde a década de 1790, com a promulgação do primeiro Fugitive Slave Act, o qual garantia o direito de um proprietário de escravo recuperá-lo em caso de fuga, os escravos que fugiam não detinham mecanismos para sustentar essa fuga, sendo assim levados de volta às condições degradantes que viviam (Baker, 2017).

Com a intervenção das "sanctuary cities", ou cidades-santuário, no sentido de proteger esses escravos fugitivos, se iniciam as primeiras divergências entre o governo federal, o qual visava atender às pressões dos proprietários de escravos, e os governos subnacionais. Cada vez mais, os Estados do norte, como a Pensilvânia, Nova Jersey e Nova York, deram início ao desenvolvimento de ações sobre como lidar com esses refugiados que eram diretamente contrárias àquelas do governo central. Passaram então a aprovar leis que tentavam equilibrar as proteções legais para os escravos fugitivos, buscando garantir os direitos desses indivíduos, o que levou os proprietários de escravos a protestarem judicialmente (Baker, 2017).

A partir desse contexto surge, em 1942, o primeiro caso na Suprema Corte dos EUA contra essa iniciativa das cidades-santuário. Em Prigg vs. Pensilvânia, a Corte definiu que os escravos fugitivos eram considerados uma questão de interesse federal, e não estatal ou municipal. Isso significava que os Estados não poderiam aprovar leis nessa matéria, sejam elas no sentido de proteger os direitos legais dos escravos fugitivos ou de ajudar na sua remoção. Tal decisão deu aos proprietários de escravos uma enorme vitória em face aos governos subnacionais (Baker, 2017).

Todavia, na mesma decisão, o tribunal reafirmou também que o Congresso não poderia obrigar os oficiais dos Estados a aplicar as leis federais. Assim, esses passaram a retirar a cooperação estatal no enforcement da legislação federal, o que, naquele período, era importantíssimo para consolidação do federalismo como novo sistema de governo. De acordo com Baker (2017), isso significava que os administradores e a polícia locais foram instruídos a não deter suspeitos de serem escravos fugitivos e nem obedecer a mandados, sendo que as prisões dos estados passaram a ser fechadas para interferência federal. Ao tomar tais iniciativas, as cidades-santuário tornaram-se fortalezas no sentido de proteção a esses indivíduos, mostrando sua forte oposição à aplicação da lei federal.

No mesmo sentido de oferecer proteção a indivíduos vulneráveis, surge o chamado "Movimento Santuário" na década de 1980. Esse período coincide com uma fase extremamente importante para o ganho de relevância no posicionamento internacional dos governos subnacionais, principalmente nos sistemas federativos, o qual desafiou as concepções tradicionais associadas à teoria realista das Relações Internacionais. Essencialmente, esse momento representou uma transformação nos estudos de outros atores do sistema internacional, por se perceber a realidade transnacional adquirida ao redor do globo. Para John Kline (cit. in. Blase2003), a intensificação do processo de globalização - visualizada principalmente nesse período corroeu a diferenciação que se fazia das esferas domésticas e externas, o que levou a uma alteração dos interesses dos governos estaduais e locais. 


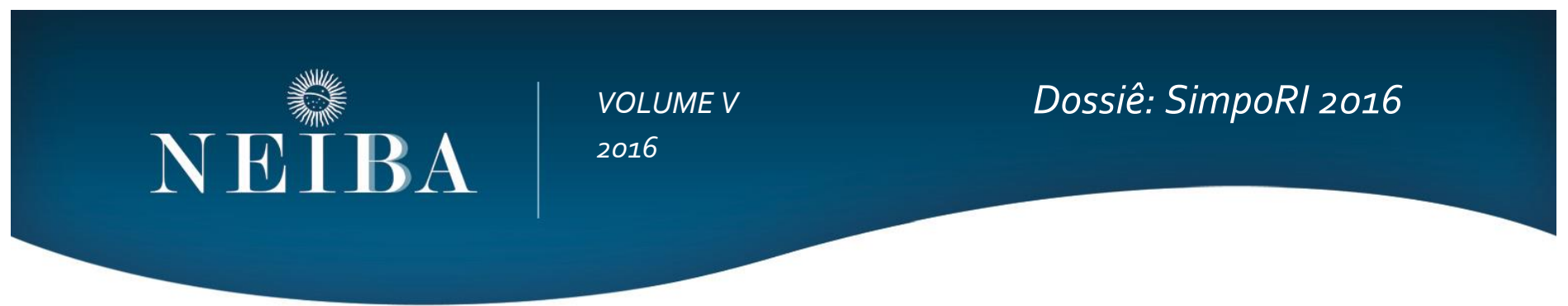

Pelo fato de agora as localidades perceberem mais diretamente os efeitos de acontecimentos estrangeiros em suas jurisdições, todas as variáveis envolvendo esse novo âmbito também passam a ser consideradas na formulação de suas políticas e projetos, além de serem consideradas também para a execução destes (Duchacek, 1990). Então, a partir desse cenário pode-se dizer que os atores subnacionais passaram a adquirir um papel estratégico para o desenvolvimento da economia nacional e local, visto o surgimento de novos níveis de governança que vão além do Estado-nação. Em face à necessidade das últimas décadas de operar em uma escala muito maior do que os problemas locais, o plano internacional passou a ser uma possibilidade de atuação desses novos níveis.

É nesse ponto que a relação entre atividade internacional de governos subnacionais e migração se tangenciam. Com a intensificação da globalização, os fluxos migratórios também atingiram níveis altos, levando os Estados a lidarem com essa questão de forma mais enfática. Todavia, é o plano local que tem de lidar com a população imigrante, provendo acesso a serviços básicos e estruturando a realidade para recebe-los. Assim, por serem afetados de forma direta, os governos subnacionais passaram a aumentar seu engajamento na formulação de políticas imigratórias, as quais buscam atender à seus interesses e necessidades.

No caso dos Estados Unidos, nesse sentido, não é diferente, especialmente ao se considerar as particularidades do seu federalismo. Como pode se observar, a Constituição dos EUA ratificada em 1789 forneceu ao país uma centralização de poder ao redor de um governo federal. No entanto, o texto constitucional não expressa de forma explícita uma designação clara daquilo que seriam poderes estatais ou nacionais na arena internacional, apenas proibindo o envolvimento dos estados em tratados ou alianças. Mesmo com a aprovação da Décima Emenda à Constituição que diz: "Os poderes não delegados aos Estados Unidos pela Constituição, nem por ela negados aos
Estados, são reservados aos Estados ou ao povo", ainda existem muitos debates ao redor dessa questão, sendo essa considerada a grande brecha constitucional para a atuação subnacional nos EUA. Por esta razão, os entes federativos passaram a buscar mais o meio internacional a partir das brechas constitucionais que encontravam, mas, além disso, passaram a buscar inserção em questões políticas também, as quais teoricamente seriam de domínio federal. (Estados Unidos da América, 1787).

Nesse contexto, o Movimento Santuário surgiu com o objetivo de oferecer proteção aos refugiados não documentados que fugiam das guerras que vinham ocorrendo na América Central, visto o cenário imigratório que o país passava no momento. Esse movimento tornou-se expressão da procura por inserção e autonomia na condução de políticas, principalmente quando a forma com que o governo nacional as administra não expressa os interesses e valores dos governos subnacionais.

A situação em diversos países vizinhos aos EUA, como em El Salvador e na Guatemala, era caótica. No primeiro, o governo salvadorenho foi tomado pelo controle militar, o que, de fato, marcou o início dos assassinatos em massa da população; estima-se que de $18 \mathrm{mil}$ a $20 \mathrm{mil}$ pessoas foram mortas ou desapareceram apenas em 1980 no país. Por essas razões, milhares de salvadorenhos passaram a buscar refúgio contra a violência, fugindo em direção aos EUA. Já na Guatemala, em 1981, o mesmo tipo de campanha foi iniciada por parte do governo, o que levou a um êxodo semelhante rumo aos Estados Unidos (McDaniel, 2017).

Quando os sobreviventes dessas fugas foram trazidos para as cidades de Tucson e Phoenix, as igrejas locais que queriam ajudá-los descobriram que o Serviço de Imigração e Naturalização (INS) planejava devolvê-los a El Salvador sem permitir que nenhum deles solicitasse o pedido de asilo. No entanto, como nessa época os EUA já faziam a diferenciação jurídica entre refugiados e imigrantes, 


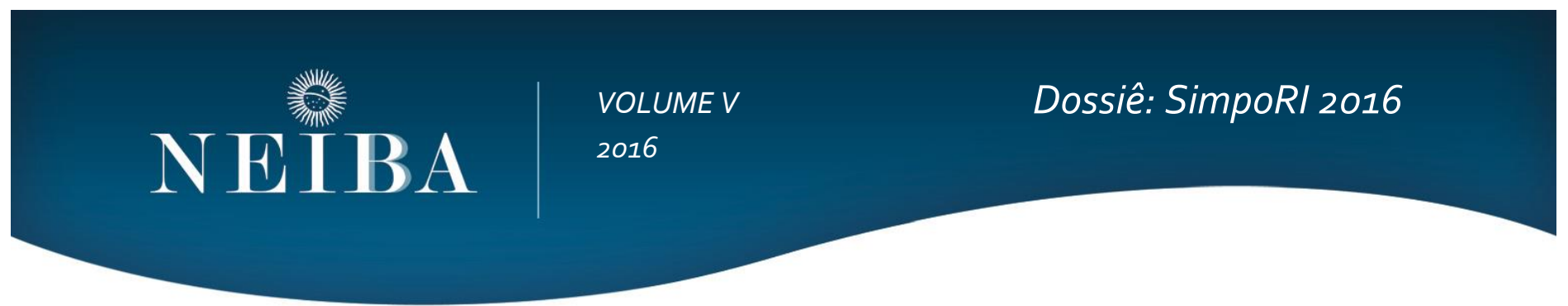

principalmente após a aprovação do RefugeeAct ${ }^{1}$ de 1980, as igrejas e congregações acreditavam que esses indivíduos deveriam ser protegidos por essas legislações. Assim, passaram a oferecer asilo aos indivíduos que comprovassem que sofriam de alguma forma perseguição em seus países de origem (McDaniel, 2017).

Dentro de um ano, a necessidade de abrigar os refugiados nos Estados Unidos tornou-se óbvia; todavia, ao contrário do esperado, o governo federal passou a apoiar os governos brutais da América Central em detrimento dos refugiados. A partir desse contexto, em 24 de março de 1982, seis congregações no Arizona e na Califórnia se declararam "santuários" e começaram a construir comunidades de apoio para o crescente número de refugiados que procuravam asilo (McDaniel, 2017).

Através de toda essa contextualização do Movimento Santuário, é importante ressaltar que, durante a década de 1980, o termo "santuário" denotava outro significado daquele que se utiliza nos dias atuais, sendo ele extremamente específico. À época, o conceito utilizado se referia a um entendimento ampliado do direito de asilo que era praticado nas culturas antigas, como a grega e egípcia. Além disso, trazia também o elemento religioso associado à perseguição que cristãos e judeus sofreram, visando assim oferecer proteção a esses indivíduos.Em 1987, mais de 400 localidades nos EUA passaram a se identificar como "cidades-santuário", sendo que as igrejas, sinagogas e mosteiros adquiriram um novo significado de "espaços sagrados", nos quais as autoridades de imigração não eram autorizadas a cumprir mandados de prisão (McDaniel, 2017).

Com o final do século $X X$ e início do século $X X I$ percebe-se que o significado adquirido pelo termo cidades- santuário sofreu uma transformação significativa em relação ao seu significado original. A ampliação do conceito, que era anteriormente associado apenas a cidades e locais sagrados que buscavam proteger refugiados, passou a ser relacionado às "sanctuary jurisdictions", ou seja, jurisdições santuárias. Essas jurisdições dentro dos EUA incluem as cidades, os condados - divisões administrativas dos estados - e os estados $^{2}$.

Além de terem a sua significância ampliada, as cidades-santuário começaram a ganhar grande projeção midiática a partir dos governos de George W. Bush e Barack Obama, devido às políticas desenvolvidas por esses. Principalmente durante a administração Obama (2009-2017), em que houve uma tentativa de reforma imigratória nos EUA e ocorreram números recorde de deportações, as cidadessantuário passaram a desafiar de forma mais recorrente a ICE (Immigrationand Customs Enforcement) e a própria forma de condução da política imigratória do governo federal.

Dessa maneira, as cidades-santuário se espalharam pelos Estados Unidos. Atualmente, de acordo com levantamento realizado por um relatório do ICE, cerca de 170 jurisdições mantêm esse status (ICE, 2017). No entanto, o Centro de Estudos sobre Imigração, uma organização nãogovernamental, afirma que existem pelo menos mais de 300 jurisdições que contrariam as determinações federais, de acordo com uma atualização de seu relatório ao final de maio de 2018, como pode ser observado na Figura 1. Atualmente, são os principais exemplos de cidades-santuário Nova lorque, Los Angeles e Chicago, contando com aproximadamente 1.150.000, 1.000.000 e 425.000 imigrantes ilegais cada, respectivamente (GriffithandVaughan, 2018).

${ }^{1} \mathrm{O}$ RefugeeAct de 1980 foi a primeira grande alteração nas leis imigratórias dos EUA. Essa lei definiu os refugiados como aqueles indivíduos que se encontravam fora de seus países de origem, que eram incapazes ou indispostos a retornarem a esses, devido a motivos de perseguição por raça, religião, grupo social ou opinião política (ESTADOS UNIDOS DA AMÉRICA, 1980).

\footnotetext{
${ }^{2}$ Cabe ressaltar que mesmo com a mudança do termo em inglês, o termo em português utilizado neste trabalho continuará sendo cidades-santuário, adotando a significação mais recente desse.
} 


\section{NEIBA}

Figura 1 - A localização das cidades-santuário nos

EUA

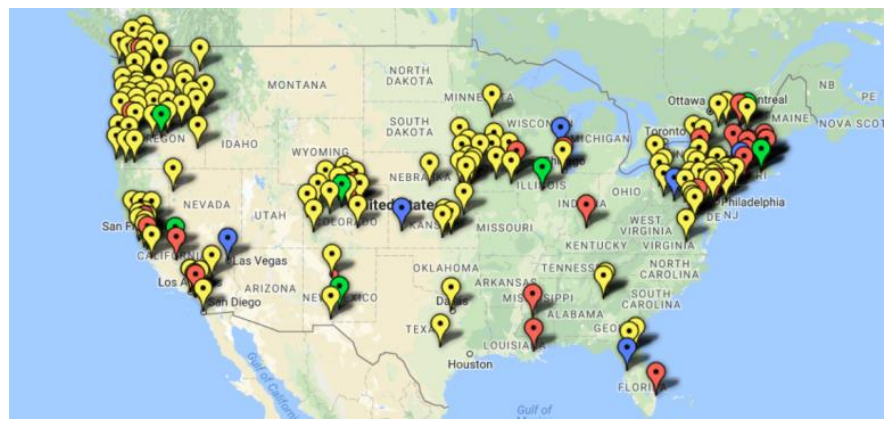

Fonte: Griffith and Vaughan, 2018.

Dada a quantidade de entes federativos que se denomina santuário nos dias atuais, é importante definir como então as cidades-santuário passaram a ser identificadas, levando em consideração a mudança em sua concepção. Até o ano de 2016 não havia nenhuma publicação oficial do governo federal reconhecendo as características das cidades-santuário. Todavia, ao final de janeiro de 2017 através de um memorando elaborado pelo então Procurador-Geral dos EUA, Jeff Sessions, nota-se que há um reconhecimento por parte do governo central da relevância das cidades-santuário no contexto do país, principalmente através dessa definição. Assim, definem-se cidades-santuário como aquelas jurisdições que se recusam a compartilhar informações relacionadas ao status de imigração com funcionários federais (Washington Times, 2017).

Desde a vitória de Donald Trump na eleição presidencial em novembro de 2016, diversas cidadessantuário já haviam se pronunciado acerca das medidas que o então Presidente eleito prometia colocar em prática. À época, essas localidades reiteraram seu compromisso com as populações imigrantes ao fazer declarações públicas de contrariedade à política migratória que seria implementada em 2017, considerando principalmente o caráter xenofóbico e excludente que seria incorporado às legislações. Prefeitos de Boston, Providence, Chicago, Jersey City, Seattle, Filadélfia, Los Angeles, São Francisco, Washington D.C. e Nova lorque prometeram proteger os imigrantes e tomar atitudes contra os planos de deportação de Trump (AFP, 2016).

Assim, a partir do início do mandato do Presidente Trump e as primeiras iniciativas tomadas pela administração no sentido de reformular a política migratória, as cidadessantuário passaram a agir principalmente de duas formas:através de um movimento de criação de políticas locais de combate às ordens da polícia federal imigratória (essencialmente se pautando em políticas "don'task" e "don'ttell")e de proteção do imigrante, além de também se empenharem em diversas batalhas judiciais contra as medidas instituídas pelo governo federal.

Em relação às formas de resistência direta às imposições do governo federal, as cidades-santuário geralmente se pautam em três: políticas "don'task", "don'ttell" e "don'tenforce". Respectivamente, essas disposições envolvem: limitação às investigações sobre o status de imigração de uma pessoa, a menos que investigue outra atividade ilegal além do simples status de imigração; limitações à divulgação às autoridades federais de informações sobre status de imigração; e limitações às detenções por violação das leis de imigração (Batt, 2016).

Nesse sentido, duas localidades se destacam ao exercerem seu papel de cidades-santuário: o Estado da Califórnia e o de Nova lorque. Em relação ao estado da Califórnia, essa é uma das jurisdições santuárias mais convictas e tradicionais dos EUA, precursor na luta contra os esforços xenófobos de Trump. No mês de outubro de 2017, o governador Jerry Brown assinou um conjunto de onze leis que visam proteger imigrantes não documentados das ações do governo federal, fornecer assistência aos estudantes, combater abusos e ameaças de deportação, além de 


\section{NEIBA}

restringir a colaboração com agentes de imigração (Felipe, 2017). De forma a institucionalizar esse esforço, em setembro de 2017 todo estado passou a adquirir o status de santuário através da aprovação da SB-54.

Além dessas iniciativas, destacam-se também aquelas tomadas pelas principais cidades-santuário do estado da Califórnia: Los Angeles e São Francisco. Ambas as localidades, somadas ao condado de Santa Clara, buscaram obter uma liminar contra a Ordem Executiva 13768, a qual o Presidente Trump visava privar as cidades-santuário e Estados de fundos federais. De acordo com o prefeito de Los Angeles, Eric Garcetti, essa ação seria totalmente inconstitucional e que as cidades lutariam para proteger a dignidade de todos que lá residem: "We will fight to protect the safety and dignity of all Angelenos, and we will work closely with our representatives in Congress to make sure that Los Angeles does not go without federal resources that help protect millions of people every day" (Chou, 2017).

Ainda, a cidade de Los Angeles, a partir de uma determinação do prefeito, passou a impedir que funcionários da cidade cooperassem com funcionários federais de imigração. Ainda, a polícia nos portos e aeroportos foi instruída a se abster de investigar o status de imigração de uma pessoa ou realizar qualquer tipo de abordagem. Esse tipo de atitude mostra que quaisquer funcionários da cidade seriam obrigados a seguir as políticas do Departamento de Polícia de Los Angeles em relação à política de imigração, ou seja, contrarias àquelas desenvolvidas em âmbito federal (Chou, 2017).

No que tange às iniciativas tomadas pela cidade e o Estado de Nova lorque, percebe-se que o leque se torna mais amplo que na Califórnia. Nesse Estado, percebe-se que as principais autoridades, como o prefeito Bill de Blasio, o governador Andrew Cuomo e o Procurador Geral do Estado, Eric Schneiderman, suportam e buscam criar maneiras de proteger os imigrantes que ali vivem.
A primeira medida que merece destaque é o guia de janeiro de 2017 intitulado "Guidance Concerning Local Authority Participation In Immigration Enforcement And Model Sanctuary Provisions" escrito pelo ex-Procurador Geral do Estado de Nova lorque, o qual descreve primeiro a paisagem legal que rege o envolvimento das jurisdições locais na investigação e aplicação das leis de imigração, para que as autoridades locais compreendam em que medida elas podem se recusar a participar dessas atividades. O guia também fornece um idioma modelo que as localidades podem utilizar - e que é consistente com a lei federal atual para limitar a aplicação da lei e a participação das agências locais nas atividades federais de imigração. A linguagem modelo baseia-se em uma revisão das provisões dos numerosos estados e cidades do país que já agiram para proteger essa população vulnerável (Schneiderman, 2017).

Outra iniciativa estatal inovadora foi a criação de um fundo para imigrantes não documentados em abril de 2017. Foram direcionados cerca de US\$10 milhões do orçamento fiscal de 2018 para desenvolver esse projeto, que visa prover acesso jurídico a todos os imigrantes que necessitem, principalmente aqueles que estão enfrentando risco de deportação. O fundo foi nomeado de Liberty Defense Project e faz parte de uma parceria público-privada, havendo também a participação de ONGs, as quais já contribuíram com mais de US\$1.500.000, aumentando assim a verba do fundo (Blanco, 2017). Além dessas medidas, a própria cidade de Nova lorque também procura desenvolver projetos em prol da situação do imigrante e reafirma seu compromisso de lutar contra as medidas imigratórias federais. Nesse sentido, o prefeito Bill de Blasio afirmou que não seriam feitas vistorias aleatórias na população e que a cidade não iria fornecer às autoridades federais nenhuma informação acerca da documentação dos imigrantes.

Ainda, é importante ressaltar o papel que as cidades-santuário têm atualmente na condução de batalhas judiciais contra a administração Trump. Desde sua campanha presidencial, Donald Trump já mostrava que sua política 


\section{NEIB}

imigratória seria extremamente restrita e tentaria modificar condutas vigentes, algo que se concretizou logo nos primeiros dias de seu governo e continua a ser visto desde sua posse.

Uma de suas primeiras medidas foi instaurar duas ordens executivas, as quais ficaram conhecidas como "muslimbans" por justamente impedir a entrada de indivíduos de origem de alguns países muçulmanos por um período e por suspender o programa de recepção de refugiados. A primeira, a Ordem Executiva 13769, foi combatida inicialmente por Nova York, seguido por Seattle, Califórnia e mais outras treze jurisdições, as quais apoiavam que essa ordem fosse suspensa por ser de cunho xenofóbico. Devido ao combate a sua primeira ordem executiva, Trump instaurou a Ordem Executiva 13780, extremamente semelhante à 13769, pois só removia o Iraque da lista de países com entrada proibida aos EUA. Da mesma forma que a primeira, essa ordem também foi combatida e suspensa por tribunais de apelação e federais; no entanto, em junho de 2017 a Suprema Corte aceita que parte da Ordem 13780 entrasse em vigor(Schallhorn, 2018).

Em setembro de 2017, ao expirar o período da ordem 13780, uma nova Ordem Executiva foi promulgada, adicionando restrições à entrada de oficiais da Coreia do Norte e Venezuela. Novamente as cidades-santuário iniciaram processos judiciais contra essa medida, mas tiveram sucesso apenas em parte, pois parte da ordem realmente entrou em vigor. No entanto, em meio a essas disputas, a Suprema Corte dos EUA decidiu abrir o processo, requerido pelo Havaí, para decidir se o banimento fere a Constituição ou as leis imigratórias vigentes. Tal aceitação do processo foi considerada uma vitória por dezesseis entes federativos, dentre eles a Califórnia, Connecticut, Maryland e Washington, os quais elaboraram um documento que apoia formalmente o Havaí em seu pleito (Schallhorn, 2018). Todavia, ao final do mês de junho de 2018, a Suprema Corte decidiu liberar a entrada em vigor dessa ordem executiva, se posicionando a favor do governo federal.
No entanto, mesmo com essa variedade de medidas os imigrantes não estão completamente seguros. Dados apontam que em 2017 o número de prisões realizadas pela ICE aumentou em 30\% se comparado ao ano anterior (Bialik, 2018). Ainda, relatos mostram que a atuação da polícia de imigração, mesmo nessas jurisdições, tem se tornado cada vez mais impositiva e sorrateira, havendo agora prisões em locais sagrados, como templos e igrejas que são frequentados por imigrantes, e cortes judiciais; esses locais, normalmente, não seriam alvo de buscas por parte da ICE.

Tendo em vista esse cenário conturbado em que de um lado estão as cidades-santuário, havendo aumento nas medidas de proteção ao imigrante, e por outro, há o governo federal ampliando os poderes de sua polícia de imigração e intensificando medidas contra essa população, há o caso do Texas. Como será apontado na próxima seção, em concomitância com a promulgação de medidas antiimigração de Trump, o senado do Texas propôs para votação aquela que viria a ser apontada como a legislação mais perigosa aos imigrantes - mesmo quando comparada a lei do Arizona de $2010^{3}$ - a SB-4 (Dart, 2018).

\section{O contra movimento do Texas: a lei SB-4 de 2017} e suas consequências

O Texas é o segundo estado mais populoso dos EUA, com cerca de 28 milhões de habitantes de acordo com dados de 2016. No entanto, mesmo sendo um estado conservador, com cerca de $44 \%$ da população branca, os outros $66 \%$ são representação da população latina (39\%), afrodescendentes (12\%) e asiáticos (5\%). Dessa forma, o estado é considerado um dos cinco nos EUA formado por uma "maioria de minorias", isto é, com a maior parte de sua

\footnotetext{
3 A SB-1070 foi uma proposta de lei aprovada no Senado do estado do Arizona em 2010 e inspirou, desde então, uma série de novas leis em outros estados dos EUA. O texto exige que a polícia determine o status de imigração de alguém preso ou detido quando houver uma "suspeita razoável" de que a pessoa não está legalmente nos EUA (ACLU, 2018).
} 


\section{NEIBA}

população constituída por aqueles grupos considerados minoritários (Núnez, 2018).

Essa contextualização demográfica do Texas tornase extremamente importante ao tratar do movimento antiimigratório que vem sendo estabelecido no estado. Por mais que nenhuma jurisdição texana tenha se declarado santuário, desde o início de 2017 tem sido percebido uma articulação, por parte do governo estadual, extremamente contrária a quaisquer ações que se assemelhem àquelas tomadas pelas cidades-santuário - descritas na seção anterior.

Esse tipo de processo se assemelha ao movimento do início da década de 2010, no qual diversos estados dos EUA, como Alabama, Geórgia, Indiana, Carolina do Sul e Utah adotaram medidas similares àquelas do Arizona, visando intensificar a fiscalização de status imigratório, seja de forma mais informal - em blitz de trânsito, supermercados, etc - como também formal, por exemplo no momento de inscrição de crianças em escolas públicas. Dessa maneira, com a retomada do conservadorismo estadunidense a partir da eleição de Trump e as políticas por ele já implementadas, as quais reforçam a associação de imigração com um problema para o país, a proposta da lei SB-4 surge no Texas no final de 2016.

O estopim para o desenvolvimento do projeto surgiu como resposta à declaração da xerife Sally Hernandez, do condado de Travis, a qual ela relatava que ela cumpriria o seu papel de polícia local no combate à crimes e que somente entraria em contato com a polícia de imigração - o ICE - em casos graves, como assassinatos ou agressão, por exemplo. Isso significaria que a colaboração entre ambas as polícias seria mínima, não envolvendo o status de imigração de indivíduos que cometessem delitos menores, mas ainda atendendo a mandatos de prisão e repassando casos sérios. Esse tipo de protocolo estaria em conformidade com a legislação dos EUA (ElizondandHammonds, 2017).
Além desse caso, o governador Greg Abbott citou também preocupações com a segurança pública do Texas devido a um incidente particular que um imigrante indocumentado, o qual, mesmo após ser preso e deportado diversas vezes, desencadeou uma onda de crimes em no estado, matando duas pessoas e sequestrando outra. Assim, - governador aproveitou a oportunidade para tornar o projeto de lei contra santuário uma das suas principais prioridades legislativas e afirmou que "para proteger os texanos de um perigo mortal, devemos insistir que as leis sejam seguidas"(Elizond and Hammonds, 2017).

Nesse sentido, o Senado do Texas logo no segundo mês de 2017 aprovou a SB-4, mas devido a mudanças requisitadas pelo governador, a lei só foi revisada em maio e deveria iniciar sua implementação em setembro, sendo o texto legislativo mais punitivo principalmente para imigrantes indocumentados. De acordo com Núñez (2018), os principais pontos abarcados pela lei são:

1. Torna-se permitido que a polícia - incluindo a polícia do campus universitário - questione o status de imigração de qualquer pessoa que detenha ou prenda. Isso inclui motoristas e passageiros que forem parados em fiscalizações de trânsito;

2. Exige-se que os chefes de polícia e os xerifes dos condados cooperem com os funcionários federais de imigração honrando os pedidos de deportação do ICE, estando proibidos de "adotar, impor ou endossar" políticas que proíbam ou limitem o cumprimento das leis de imigração.Ainda, as cadeias locais devem deter imigrantes indocumentados que foram detidos até que o ICE possa buscá-los, se o ICE o solicitar. Caso o policial não coopere, é passível de multa de 25 mil dólares por dia, prisão ou perda do cargo;

3. A SB-4 não se aplica a distritos escolares (incluindo polícia escolar), polícias afiliadas a religião, escolas abertas, distritos hospitalares, centros comunitários e 


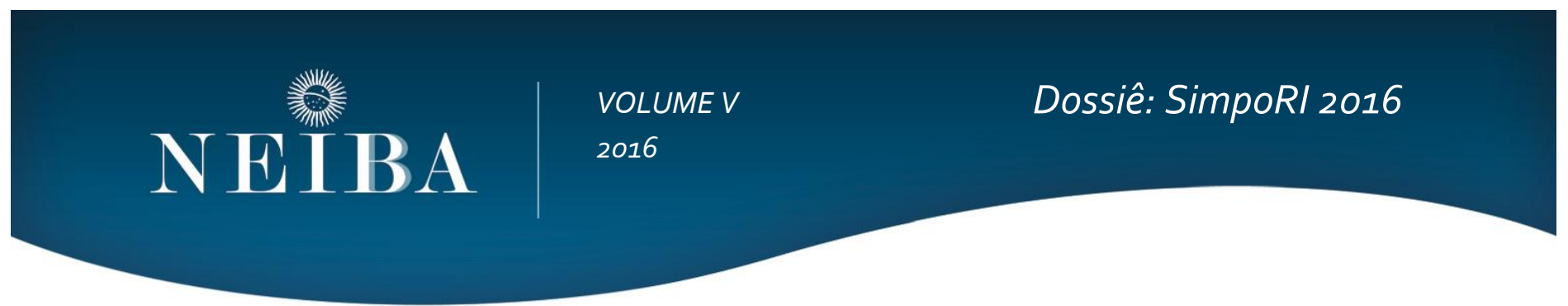

autoridades de saúde mental. No entanto, a polícia local chamada às escolas pode perguntar sobre o status de imigração de uma pessoa, exceto de pais ou alunos, exceto conforme permitido pela lei federal.

A partir de tais pontos, a SB-4 ficou conhecida como lei "show me your papers" ("mostre-me seus documentos"), justamente por colocar em risco o status imigratório de qualquer indivíduo abordado pela polícia local, e não apenas daqueles que se envolvam em algum tipo de crime. Com a aprovação dessa lei, o Texas passa a se encaixar nos critérios do que se considera um "estado hostil"; de acordo com Latimer (2016), esse tipo de estado é justamente aquele com leis desenvolvidas para identificar imigrantes. Uma das possíveis consequências para esse tipo de comportamento é a perda de capital humano, levando mesmo imigrantes legais a evitarem essas localidades.

Embora a lei inclua uma cláusula anti-discriminação, esta cláusula é relativamente vaga. O texto afirma que uma entidade de polícia local ou departamento de polícia do campusnão pode considerar a raça, cor, religião, idioma ou nacionalidade enquanto se aplica as leis de imigração (Elizond and Hammonds, 2017). O problema está no fato de que essa disposição acaba não cumprindo o seu propósito de proteger contra a discriminação, pois como é comum, são sobrepostas outras justificativas a um pré-julgamento que ocorre, como por exemplo, um comportamento suspeito.

Somada a essa questão, os imigrantes no Texas contam com um grande revés no que tange a sua proteção legal. De outubro de 2000 a fevereiro de 2018 , menos de $30 \%$ - 213.197 de 733.125 - de imigrantes em processo de deportação no Texas contaram com a representação de um advogado, de acordo com a Central de Acesso a Registros Transacionais da Universidade de Syracuse. Isso ocorre devido ao fato de as violações de imigração serem, em grande parte, de natureza civil, e, no Texas, os imigrantes indocumentados não têm garantido o direito a um advogado nesses tipos de casos. Essa taxa é uma das mais baixas do país, atrás apenas do Arizona e da Louisiana (Aguilarand Cameron, 2018).

Para além dessas questões, os grupos e organizações contrários a lei SB-4 contam com diversos outros argumentos que os fazem repudiar essa legislação. Em primeiro lugar, acreditam que a legislação é redundante, inconstitucional e baseada no fomento do medo ao imigrante. Em relação a esse ponto, argumenta-se discriminação à comunidade imigrante desde antes de sua formulação, ao se fazer uso do caso apontado pelo governador Abbott como exemplo. Como apontam Elizond e Hammonds (2017), para esses grupos, o caso que serviu como estopim à criação do projeto de lei não teria sido tão politizado se o imigrante em questão fosse um cidadão americano branco.

Ainda, é imprescindível destacar que leis como o SB4 destroem a relação entre as forças policiais locais e as comunidades de imigrantes. Quando há confiança na polícia, os imigrantes são mais propensos a denunciar crimes, servir de testemunhas e cooperar com as autoridades, sem medo de deportação. Quando a polícia se envolve em deportações, causa desconfiança e medo entre a polícia e as comunidades minoritárias, reduzindo a cooperação e a disposição para denunciar crimes. De acordo com o chefe de polícia de Houston, ArtAcevedo, os efeitos da criação e aprovação inicial da SB-4 já podem ser sentidos. Dados dos três primeiros meses de 2017 mostram que os latinos de sua cidade relataram $13 \%$ menos crimes violentos, $43 \%$ menos estupros e agressões sexuais, $12 \%$ menos agressões agravadas e $12 \%$ menos assaltos em comparação com o mesmo período de 2016 (Núñez, 2018).

Pensando no lado econômico, desde a aprovação da lei, representantes dos setores de negócios, governos locais e de educação superior do Texas mostravam que ela poderia causar bilhões de dólares em prejuízos à economia do estado. Utilizando dados da Pesquisa da Comunidade Americana de 2015 e do Escritório de Análise Econômica, 


\section{NEİBA}

estimou-se em 2017 que o estado perderia aproximadamente US\$223 milhões em impostos estaduais e locais e mais de US\$ 5 bilhões do PIB devido a SB-4. De acordo com Aguilar (2017), esses cálculos são baseados nos dados relacionados a taxa de emprego, lucros, impostos e PIB do Texas.

Por outro lado, os proponentes da SB-4 também ganharam diversos apoiadores dentro das casas legislativas e na população. Eles argumentam que a lei promove uma maior sensação de segurança entre todos os residentes, incluindo as comunidades de imigrantes. Para esse grupo, ao garantir que as entidades locais não proíbam a aplicação das leis federais de imigração, tanto os funcionários locais quanto as autoridades federais podem trabalhar em conjunto para manter os criminosos fora das ruas. Ainda, afirmam que a lei não altera muito a vida dos texanos, já que a maioriadas cidades já operam em conformidade com a lei federal; assim, a SB-4 apenas geraria uniformidade aos padrões do estado (Elizond and Hammonds, 2017).

Tais divergências de opiniões levaram o Texas a se ver em meio a uma disputa judicial em torno da entrada em vigor da SB-4, prevista para setembro de 2017. Logo que anunciada, diversas localidades importantes do estado iniciaram processos contra o governo do estado, dentre elas, Austin, Dallas, o condado de El Paso e Houston. Vis-à-vis a quantidade de processos, as cidades decidiram por se unir e abriram um novo processo unificado, visando derrubar a lei. Os principais argumentos utilizados pelos requerentes versavam que a lei feria a Constituição dos EUA, especificamente a Primeira, Quarta e Décima Quarta Emendas, assim como a Cláusula de Supremacia Constitucional (Fernandez, 2017).

Em agosto de 2017, alguns dias antes da lei entrar em vigor, o juiz federal Orlando Garcia concedeu uma liminar proibindo o seu início enquanto o processo continuava. Em seu parecer, o juiz bloqueou as três disposições principais da lei, argumentando que as autoridades não podem demandar o status de imigração de qualquer indivíduo e que não se pode punir forças locais de polícia por terem opiniões diferentes daquela do estado no que tange a condução de abordagem de imigrantes (Fernandez, 2017).

Assim, a SB-4 ficou suspensa de agosto de 2017 até março de 2018. Em uma decisão unânime, um painel de três juízes da Corte de Apelações dos Estados Unidos do Quinto Circuito reverteu quase completamente a decisão anterior juiz Orlando, a qual havia impedido temporariamente que oficiais do Texas imponham a lei. A única ressalva do painel de apelações foi em relação a um dos elemento da lei: aquele que prevê punição às autoridades locais por "adotar, impor ou endossar" políticas que proíbam ou limitem o cumprimento das leis de imigração. Nesse ponto, os juízes mantiveram a liminar de agosto em vigor, mas disseram que isso se aplica apenas à palavra "endosso", por violação a Primeira Emenda (Astor, 2018).

Em relação às outras partes da lei, os juízes rejeitaram os argumentos dos oponentes de que, entre outras coisas, buscavam argumentar que não havia definição adequada do que seria uma conduta proibida e abriria as portas para o perfil racial.Não obstante, algumas semanas depois os oponentes da legislação, principalmente do condado de Travis e da cidade de Austin, somados aos Advogados da União Americana das Liberdades Civil (ACLU), pediram a Corte de Apelações que reconsiderasse essa decisão. Todavia, até o mês de outubro de 2018, nenhuma reconsideração foi tomada (Aguilar, 2018).

Isto posto, a lei SB-4 está atualmente em vigor no Texas. Ainda não é possível analisar as consequências desse tipo de legislação, mas como já apontado, momentos difíceis estão por vir para a população imigrante no estado. É importante ressaltar que leis estaduais como a "show me your papers" não são tão incomuns, principalmente após o caso do Arizona em 2010; no entanto, ela se destaca por incluir a verificação do status de imigração de qualquer indivíduo, além de obrigar a colaboração da polícia local com 


\section{NEIBA}

a ICE e prever até mesmo punição a oficiais locais que não sigam essas recomendações.

\section{Conclusões}

O movimento conservador que vem adquirindo força nos Estados Unidos nos últimos anos acaba ganhando, com a eleição de Donald Trump para a presidência do país em 2017, certa forma de institucionalização, principalmente após um longo período de uma administração democrata. Nesse sentido, medidas de caráter protecionista, nacionalista e, até mesmo xenofóbicas, acabam se concretizando e sendo implementadas, em prol de retomar um projeto de "America first".

Em face a esse cenário, as atividades dos governos subnacionais acabam se tornando cada vez mais necessárias. Principalmente a partir da década de 1980, período no qual o meio internacional acaba se integrando mais com as esferas domésticas e gerando consequências internas para essas localidades, esse tipo de atuação ganhou destaque ao redor do globo, não sendo diferente nos EUA. Assim, os governos subnacionais estadunidenses passaram a se inserir no desenvolvimento de políticas que, muitas vezes, eram consideradas de escopo federal.

É justamente esse o caso do Movimento Santuário dos anos 1980 e também das cidades-santuário no século $X X I$. Ao se consolidarem como um bloco de resistência às políticas imigratórias desenvolvidas pelo governo federal, essas localidades estadunidenses passam a ser consideradas refúgios a população imigrante do país. Atualmente, em face a existência de forças conservadoras tanto na sociedade quanto na administração dos EUA, esse tipo de incentivo acaba se destacando positivamente.
Portanto, frente ao governo de Trump, as cidadessantuário têm se empenhado em acabar com políticas de cunho xenofóbico ou mesmo extremista, através do enfrentamento do governo federal em âmbito judicial, mostrando assim a sustentação de uma forte posição política. Tão importante quanto esse tipo de iniciativa, também são as medidas tomadas localmente, que incentivam desde a proteção do imigrante frente a polícia local, incluindo até mesmo ações assistencialistas.

Por fim, pode-se perceber o porquê da lei SB-4 estar causando tanta polêmica no estado do Texas. Além de deixar a população imigrante integralmente à mercê do julgamento das forças policiais, leis desse cunho tem o poder de intensificar sentimentos xenofóbicos em toda a população do estado, prejudicando cada vez mais até mesmo o acesso dessa população a serviços básicos, como saúde e transporte. Relatos apontam que mesmo no período em que a lei estava em disputa judicial, indivíduos deixaram de procurar postos de saúde para cuidarem de incidentes ou atenderam a consultas médicas, mulheres deixam de relatar abusos sexuais, empregos se tornaram perigosos. Ainda, nota-se que os governantes do estado não pensaram de forma pragmática nos impactos econômicos que essa medida pode gerar no futuro, conforme apresentado anteriormente.

De forma completamente contrária ao movimento das cidades-santuário, o qual tem tentado desmistificar a imagem de perigo associada ao imigrante e ainda proteger essa população tão importante para os EUA, o Texas acabou conseguindo abrir um precedente perigoso, principalmente perante outras localidades mais conservadoras do país.Cabe agora observar esse cenário de incerteza para analisar quão profundos serão os impactos de tais medidas, tanto no Texas, quanto no restante do país. 


\section{NEIB BA}

VOLUME V

Dossiê: SimpoRI 2016

\section{6}

\section{BIBLIOGRAFIA}

ACLU. Arizona's SB 1070.Disponivel em: <https://www. aclu.org/issues/immigrants-rights/state-and-local-immigration-laws/arizonassb-1070>. (Acesso em 14 jun. 2018).

AFP (2016). NY e outras 'cidades santuário' em guerra contra plano de deportação de Trump. Disponível em:http://www.em.com.br/app/noticia/internacional/2016/11/16/interna_internacional,824339/ny-e-outras-cidades-santuario-emguerra-contra-plano-de-deportacao-d.shtml. (Acesso em 10 abr. 2017).

Aguilar, J. (2018). Critics of Texas' "sanctuary cities" law ask federal appeals court to reconsider case.Disponivel em: $<$ <ttps://www.texastribune.org/2018/03/28/critics-texas-sanctuary-cities-law-ask-federal-appeals-court-reconside>. (Acessoem 12 jun. 2018).

Aguilar, J. (2017). Report: Texas could lose billions if new immigration enforcement law stands. Disponível em: https://www.texastribune.org/2017/08/01/report-texas-could-lose-billions-if-sb4-allowed-stand. (Acessoem: 12 jun. 2018).

Aguilar, J. and Cameron, D (2018).Immigrants in Texas are among the least likely to have a lawyer, most likely to get deported.Disponivel em: <https://www.texastribune.org/2018/04/12/trump-charges-forward-immigration-enforcement-texasdetainees-are-leas/>. (Acessoem: 12 jun. 2018).

Astor, M. (2018). Texas' Ban on 'Sanctuary Cities' Can Begin, Appeals Court Rules. Disponível em:

<https://www.nytimes.com/2018/03/13/us/texas-immigration-law-sb4.html>. (Acessoem: 12 jun. 2018).

Baker, R. (2017).A Brief History of Sanctuary Cities.Disponivel em: <https://tropicsofmeta.wordpress.com/2017/02/o2/a-brief-history-ofsanctuary-cities/>. (Acesso em: 10 out. 2017).

Bhatt, R. (2016). Pushing an End to Sanctuary Cities: Will it Happen?. Michigan Journal of Race And Law, Michigan, Vol. 22, n. 1, pp.140-162.

Bialik, K. (2018).ICE arrests went up in 2017, with biggest increases in Florida, northern Texas, Oklahoma.Disponivel em: $<$ http://www.pewresearch.org/fact-tank/2018/02/08/ice-arrests-went-up-in-2017-with-biggest-increases-in-florida-northern-texasoklahoma/>. (Acessoem: 14 jun. 2018).

Blanco, O. (2017). New York to provide lawyers for immigrants facing deportation. 2017. Disponível em: $<$ http://money.cnn.com/2017/04/13/news/economy/new-york-immigrant-legal-defense-fund/index.html>. (Acessoem: 30 ago. 2017).

Blase, J. (2003). Has globalization changed U.S. Federalism? The increasing role of U.S. states in foreign affairs: Texas-Mexico Relations. Dissertation. Univesity of Texas at Austin.

Chou, E. (2017). LA mayor vows to fight Trump administration attempt to strip 'sanctuary city' funding. Disponivel em: <http://www.dailynews.com/2017/03/27/la-mayor-vows-to-fight-trump-administration-attempt-to-strip-sanctuary-city-funding/>. (Acessoem: 10 ago. 2017). 


\section{NEIBA}

Dart, T. (2018). Texas immigration law 'more dangerous' than infamous Arizona bill, critics say. Disponível em:

<https://www.theguardian.com/us-news/2017/may/og/texas-immigration-sanctuary-cities-law-arizona>. (Acessoem: 14 jun. 2018).

Duchacek, I. (1990). Perforated Sovereignties: Towards a typology of new actors in international relations. In:Michelmann, H. and Soldatos, P. (Eds).Federalism and International Relations:The Role of Subnational Units. New York: Oxford University Press, 199o. p.134 .

Elizond, A. andHammonds, C. (2017). Senate Bill 4-Impact, Implications, and Emotions. Disponível em: <https://gcswlegislativeinterns. wordpress.com/2017/05/10/senate-bill-4-impact-implications-and-emotions/>. (Acesso em: 11 jun. 2018).

Estados Unidos da América. (1787). Constituição dos Estados Unidos da América. Disponível em:

$<$ http://www.direitoshumanos.usp.br/index.php/Documentos-anteriores-\%C3\%Ao-cria\%C3\%A7\%C3\%A3o-da-Sociedade-dasNa\% $\mathrm{C}_{3} \% \mathrm{~A} 7 \% \mathrm{C}_{3} \% \mathrm{~B}_{5}$ es-at\%C3\%Ag-1919/constituicao-dos-estados-unidos-da-america-1787.html>. (Acesso em: 10 jul. 2017).

Felipe, L. (2017). Califórnia amplia proteção legal para imigrantes e vira "estado-santuário". Disponível em:

<http://agenciabrasil.ebc.com.br/internacional/noticia/2017-10/california-amplia-protecao-legal-para-imigrantes-e-vira-estado>. (Acessoem: 25 out. 2017).

Fernandez, M. (2017). Federal Judge Blocks Texas' Ban on 'Sanctuary Cities'. Disponível em:

<https://www.nytimes.com/2017/08/30/us/judge-texas-sanctuary-cities. html?login=email\&auth=login-email>. (Acessoem: 10 jun. 2018).

Griffith, B. and Vaughan, J. (2018).Maps: Sanctuary Cities, Counties, and States.Disponível em: <https://cis.org/Map-Sanctuary-CitiesCounties-and-States>. (Acessoem: 10 jun. 2018).

Immigration and Customs Enforcement (ICE). (2017). Enforcement and removal operations. Disponível em: <https://docs.google.com/viewer?url=https://cis.org/sites/cis.org/files/ddor2017_01-28too2-03\%20(1).pdf\&pdf=true>. (Acessoem: 12 out. 2017).

Latimer, B. (2016). State Anti-Immigration Laws Discourage All Latinos from Moving In. 2016. Disponível em: <https://www.nbcnews.com/news/latino/state-anti-immigration-laws-discourage-all-latinos-moving-n547396>. (Acessoem: 16 jun. 2018).

McDaniel, J. (2017). The Sanctuary Movement, Then and Now.2017. Disponível em: <http://religionandpolitics.org/2017/02/21/thesanctuary-movement-then-and-now/>. (Acessoem: 07 out. 2017).

Núñez, A. (2018). Immigration 101: What is SB 4, Texas'Immigration Law?Disponível em: <https://americasvoice.org/blog/sb4-texasimmigration-law/>. (Acessoem: 10 jun. 2018).

Schallhorn, K. (2018). Trump travel ban: Timeline of a legal journey.Disponível em:

<http://www.foxnews.com/politics/2018/04/25/trump-travel-ban-timeline-legal-journey.html>. (Acesso em: 10 jun. 2018). 


\section{NEIBA}

VOLUME V

Dossiê: SimpoRI 2016

Schneiderman, E. (2017). Guidance Concerning Local Authority Participation In Immigration Enforcement and Model Sanctuary Provisions. Disponível em: <https://ag.ny.gov/sites/default/files/guidance_and_supplement_final3.12.17.pdf>. (Acessoem: 22 ago. 2017).

Washington Times. (2017). 'Sanctuary city' definition clarified: No Justice, DHS funds for violators of U.S. code. Disponível em: <http://www.washingtontimes.com/news/2017/may/22/doj-releases-guidance-defining-sanctuary-city/>. (Acesso em: 20 jun. 2017). 